\title{
Protection of Human Lens Epithelial Cells from Oxidative Stress Damage and Cell Apoptosis by KGF-2 through the Akt/Nrf2/HO- 1 Pathway
}

\author{
Shuyu Liu $\mathbb{D}^{1}{ }^{1}$ Zi Jin $\mathbb{D}^{2},{ }^{2}$ Ruyue Xia $\mathbb{D}^{1},{ }^{1}$ Zhuoni Zheng ${ }^{\mathbb{D}},{ }^{1}$ Yi Zha $\mathbb{D}^{1},{ }^{1}$ Qiang Wang $\mathbb{D},{ }^{3}$ \\ Xinbei Wan $\mathbb{D}^{4},{ }^{4}$ Hui Yang $\mathbb{D}^{1},{ }^{1}$ and Jianqiu Cai ${ }^{1}{ }^{1}$ \\ ${ }^{1}$ Department of Ophthalmology, The Second Affiliated Hospital and Yuying Children's Hospital of Wenzhou Medical University, \\ Wenzhou 325000, China \\ ${ }^{2}$ School of Pharmaceutical Science, Wenzhou Medical University, Wenzhou 325000, China \\ ${ }^{3}$ Department of Ophthalmology, Ruian People's Hospital, Wenzhou 325000, China \\ ${ }^{4}$ Department of Epidemiology, Biostatistics and Occupational Health, McGill University, Montreal, Quebec, Canada H3A 1 G1
}

Correspondence should be addressed to Hui Yang; 337221368@qq.com and Jianqiu Cai; dcaijq@163.com

Received 17 August 2021; Revised 20 December 2021; Accepted 25 January 2022; Published 17 February 2022

Academic Editor: Dario Ramirez

Copyright (c) 2022 Shuyu Liu et al. This is an open access article distributed under the Creative Commons Attribution License, which permits unrestricted use, distribution, and reproduction in any medium, provided the original work is properly cited.

Oxidative stress exerts a significant influence on the pathogenesis of various cataracts by inducing degradation and aggregation of lens proteins and apoptosis of lens epithelial cells. Keratinocyte growth factor-2 (KGF-2) exerts a favorable cytoprotective effect against oxidative stress in vivo and in vitro. In this work, we investigated the molecular mechanisms of KGF-2 against hydrogen peroxide- $\left(\mathrm{H}_{2} \mathrm{O}_{2}^{-}\right)$induced oxidative stress and apoptosis in human lens epithelial cells (HLECs) and rat lenses. KGF-2 pretreatment could reduce $\mathrm{H}_{2} \mathrm{O}_{2}$-induced cytotoxicity as well as reactive oxygen species (ROS) accumulation. KGF-2 also increases B-cell lymphoma-2 (Bcl-2), quinine oxidoreductase-1 (NQO-1), superoxide dismutase (SOD2), and catalase (CAT) levels while decreasing the expression level of $\mathrm{Bcl} 2$-associated $\mathrm{X}(\mathrm{Bax})$ and cleaved caspase- 3 in $\mathrm{H}_{2} \mathrm{O}_{2}$-stimulated HLECs. LY294002, the phosphatidylinositol-3-kinase (PI3K)/Akt inhibitor, abolished KGF-2's effect to some extent, demonstrating that KGF-2 protected HLECs via the PI3K/Akt pathway. On the other hand, KGF-2 activated the Nrf2/HO-1 pathway by regulating the PI3K/Akt pathway. Silencing nuclear factor erythroid 2-related factor 2 (Nrf2) by targeted-siRNA and inhibiting heme oxygenase-1 (HO-1) through zinc protoporphyrin IX (ZnPP) significantly decreased cytoprotection of KGF-2. Furthermore, as revealed by lens organ culture assays, KGF-2 treatment decreased $\mathrm{H}_{2} \mathrm{O}_{2}$-induced lens opacity in a concentration-dependent manner. As demonstrated by these data, KGF-2 resisted $\mathrm{H}_{2} \mathrm{O}_{2}$-mediated apoptosis and oxidative stress in HLECs through Nrf2/HO-1 and PI3K/Akt pathways, suggesting a potential protective effect against the formation of cataracts.

\section{Introduction}

Cataract, primarily age-related, is the main reason for visual impairment and blindness across the world [1]. Currently, cataractous lens removal surgery is the only effective remedy. However, it still presents the risk of surgical complications such as posterior capsular opacification, which gives rise to the second loss of clear vision [2]. Furthermore, no efficient clinical therapies have been proposed to prevent the formation of cataracts until now. Hence, pharmacological intervention to maintain the transparency of the lens is vital.

Oxidative stress, mediated by reactive oxygen species (ROS), where DNA, proteins, lipids, and cells are damaged, is the leading contributor to the formation of cataracts $[3,4]$. In addition, oxidative stress triggers apoptosis for human lens epithelial cells (HLECs) by altering the internal environment. It is considered the common molecular basis for cataract initiation as well as progression [5]. Hydrogen peroxide $\left(\mathrm{H}_{2} \mathrm{O}_{2}\right)$ is 
a nonradical member in ROS, which damages ion pump activity in HLECs $[6,7]$. Raising $\mathrm{H}_{2} \mathrm{O}_{2}$ levels of aqueous humor are found among patients suffering cataracts which cause lens opacification in vitro [8]. $\mathrm{H}_{2} \mathrm{O}_{2}$ has gained extensive uses in inducing oxidative stress in vitro [9-11]. Subsequently, protecting HLECs against $\mathrm{H}_{2} \mathrm{O}_{2}$-induced oxidative stress and apoptosis is a potential solution to postpone cataract development.

Since no effective therapeutic drugs have been proposed for halting the formation of the cataractous lens, developing a pharmacological therapy to postpone cataract progression and ameliorate lens transparency is imperative. Evidence suggests that growth factors help prevent injury from various causes, including $\mathrm{H}_{2} \mathrm{O}_{2}$, radiation, and bleomycin [12-14]. In addition, recent studies demonstrate that growth factors possibly reduce oxidant-induced lung damage by suppressing apoptosis [15]. However, few studies have confirmed the function of growth factors in HLECs.

Keratinocyte growth factor-2 (KGF-2), also known as fibroblast growth factor-10 (FGF-10), is a critical member of the FGF family. As a multifunctional growth factor, KGF-2 plays an important role in developing various organs and tissues, including the eye [16]. For example, KGF-2 null murine embryos demonstrate agenesis in ocular glands-extra orbital and intraorbital lacrimal glands and Harderian gland [17]. Several studies have confirmed that KGF-2 can decrease oxidant-induced cell injury, inhibit cell apoptosis, and regulate cell homeostasis in numerous organs including the kidney, lung, and spinal cord [18-21]. The KGF-2 intraocular medication has been proved to be safe. Previous studies have shown that rhKGF-2 eye drop application in the long run in the rabbit corneas does neither result in any apparent systemic effects nor cause toxicity to the intraocular tissues [22]. Furthermore, the regulatory effect of KGF-2 on the PI3K/Akt pathway is confirmed $[23,24]$. As a survival pathway, the PI3K/Akt pathway modulates cell proliferation, migration, metabolism, and differentiation within diverse disorders [25]. According to increasing evidence, Akt activation can protect HLECs from oxidative stress damage and apoptosis $[26,27]$.

Nrf2 is a transcription factor that can regulate the expression of antioxidants, transporters, autophagy-related proteins, and enzymes involved in metabolism and detoxification (like heme oxygenase-1 (HO-1)) [28]. Studies have also suggested that PI3K/Akt signaling can regulate Nrf2 expression [29]. Previous studies have elucidated that Nrf2 exerts a dominant influence on protecting the lens from oxidative stress [30]. The activation of Nrf2 may lower oxidative stress and prevent cataract formation [31]. As a result, Nrf2 may play the role of a promising therapeutic target for cataract treatment.

Therefore, we adopted $\mathrm{H}_{2} \mathrm{O}_{2}$-mediated HLECs and rat lenses as study models and for the first time demonstrated that KGF-2 may protect HLECs against oxidative stress-mediated apoptosis via the Akt/Nrf2/HO-1 pathway and may prove beneficial for treating cataracts associated with oxidative stress.

\section{Materials and Methods}

2.1. Reagents and Antibodies. KGF-2 was provided by the School of Pharmacy, Wenzhou Medical University (Wen- zhou, China). Antibodies of p-Akt (\#4060), Akt (\#4685), cleaved caspase-3 (\#9664), Bcl-2 (\#4223), and Bax (\#2772) were provided by Cell Signaling Technology (Danvers, MA, USA). Antibodies of Nrf2 (ab137550) and the PI3K/ Akt inhibitor LY294002 (ab120243) were provided by Abcam (Cambridge, MA, USA). Antibodies of $\beta$-actin (20536-1-AP), HO-1 (27282-1-AP), NQO-1 (11451-1-AP), CAT (21260-1-AP), SOD2 (24127-1-AP), and horseradish peroxidase-conjugated goat antimouse/rabbit secondary antibodies (SA00001-1 or SA00001-2) came from ProteinTech (Rosemont, USA). Hydrogen peroxide $\left(\mathrm{H}_{2} \mathrm{O}_{2}\right.$, \#349887), zinc protoporphyrin IX (ZnPP, \#282820) and 3(4,5-dimethylthiazol-2-yl)-2,5-diphenyltetrazolium bromide (MTT, M2128), and dimethyl sulfoxide (DMSO, D8418) came from Sigma-Aldrich (St. Louis, MO, USA). The reagents of cell culture were obtained from Gibco (Grand Island, NY, USA). The fluorescent dyes $2^{\prime}, 7^{\prime}$-dichlorodihydrofluorescein diacetate (DCFH-DA, S0033) and Annexin $\mathrm{V}$-FITC/PI apoptosis detection kit (C1062L) were provided by Beyotime (Shanghai, China). Nrf2-small interfering RNA and fluorescein-conjugated control siRNA (sc-37030 and sc-36869) were provided by Santa Cruz Biotechnology Inc. (CA, USA).

2.2. Cell Culture and Treatment. HLECs obtained from American Type Culture Collection (ATCC, Manassas, VA, USA) were incubated by Modified Dulbecco's Eagle's medium (DMEM) supplemented with heat-inactivated $\left(56^{\circ} \mathrm{C}, 0.5 \mathrm{~h}\right) 15 \%$ fetal bovine serum $(\mathrm{FBS}), 100 \mathrm{U} / \mathrm{mL}$ penicillin, plus $100 \mathrm{mg} / \mathrm{mL}$ streptomycin in humidified $5 \% \mathrm{CO}_{2}$ at $37^{\circ} \mathrm{C}$. Cells underwent subculture regularly every 2 or 3 days. When reaching $70 \%$ confluence, cells received treatment immediately using the indicated $\mathrm{H}_{2} \mathrm{O}_{2}$ concentration for $12 \mathrm{~h}$ or pretreatment at various KGF-2 concentrations for $2 \mathrm{~h}$ before $\mathrm{H}_{2} \mathrm{O}_{2}$ treatment. For continually determining how PI3K/Akt activation affected oxidative injury, cells first received pretreatment with PI3K inhibitor LY294002 $(20 \mu \mathrm{M})$ for $2 \mathrm{~h}$.

2.3. Cell Viability Measurement. The MTT assay was performed to assess cell viability. HLECs $\left(2 \times 10^{4} /\right.$ well $)$ were inoculated onto 96-well plates. Cells were incubated at varying $\mathrm{H}_{2} \mathrm{O}_{2}$ concentrations $(0,12.5,25,50,100,200,400$, and $800 \mu \mathrm{M})$ for $6,9,12,18$ and $24 \mathrm{~h}$ or pretreated by KGF-2 for $24 \mathrm{~h}$ at varying concentrations $(0,12.5,25,50,100$, and $200 \mu \mathrm{g} / \mathrm{mL}$ ) and sometimes pretreated by KGF-2 for $2 \mathrm{~h}$ at varying concentrations $(0,12.5,25,50,100$, and $200 \mu \mathrm{g} /$ $\mathrm{mL})$; then, $\mathrm{H}_{2} \mathrm{O}_{2}(100 \mu \mathrm{M})$ was added to treat cells for $12 \mathrm{~h}$. At times, cells underwent pretreatment initially with $10 \mu \mathrm{M}$ zinc protoporphyrin IX (ZnPP, the HO-1 inhibitor) for $30 \mathrm{~min}$, followed by $2 \mathrm{~h}$ treatment using $50 \mu \mathrm{g} / \mathrm{mL}$ KGF-2 prior to $12 \mathrm{~h}$ incubation using $\mathrm{H}_{2} \mathrm{O}_{2}(100 \mu \mathrm{M})$. HLECs underwent $4 \mathrm{~h}$ incubation using MTT solution $(20 \mu \mathrm{L}, 5 \mathrm{mg} / \mathrm{mL})$ under $37^{\circ} \mathrm{C}$. Besides, the culture medium was substituted by $150 \mu \mathrm{L}$ Thereafter, DMSO was added for dissolving formazan crystals following incubation. Afterwards, optical density was calculated with $490 \mathrm{~nm}$ wavelength with a microplate reader (Molecular Devices, Sunnyvale, CA, USA). 
2.4. Apoptosis Analysis. Flow cytometric analysis was used to measure cell apoptosis in accordance with the protocol offered by Annexin V-FITC/PI apoptosis kit. Briefly, we exposed HLECs to $\mathrm{H}_{2} \mathrm{O}_{2}(100 \mu \mathrm{M})$ for $12 \mathrm{~h}$ or pretreated with 12.5 or $50 \mu \mathrm{g} / \mathrm{mL} \mathrm{KGF-2} \mathrm{for} 2 \mathrm{~h}$ and then treated with $\mathrm{H}_{2} \mathrm{O}_{2}(100 \mu \mathrm{M})$ for another $12 \mathrm{~h}$. In total, Annexin V-FITC $(5 \mu \mathrm{L})$ together with PI $(10 \mu \mathrm{L})$, PI was added, followed by 15 min tube incubation in dark. The apoptotic rate was later quantitatively analyzed with the use of a flow cytometer (FACScan, Becton-Dickinson, USA).

2.5. Determination of Intracellular Redox State. Intracellular ROS levels were detected with flow cytometry. We inoculated HLECs $\left(4 \times 10^{5} /\right.$ well $)$ into the 6 -well plate. On the next day, we exposed cells to $\mathrm{H}_{2} \mathrm{O}_{2}(100 \mu \mathrm{M})$ for $12 \mathrm{~h}$ or pretreated with 12.5 or $50 \mu \mathrm{g} / \mathrm{mL} \mathrm{KGF-2} \mathrm{for} 2 \mathrm{~h}$ and then treated them with $\mathrm{H}_{2} \mathrm{O}_{2}(100 \mu \mathrm{M})$ for another $12 \mathrm{~h}$. Afterwards, a DCFH-DA reagent $(10 \mu \mathrm{M} / \mathrm{L})$ was utilized to incubate cells under $37^{\circ} \mathrm{C}$ for $0.5 \mathrm{~h}$. ROS generation was finally evaluated using fluorescence microscopy and a FACScan flow cytometer (FACScan, Becton-Dickinson, USA).

2.6. Western Blot Analysis. HLECs treated above were collected and lysed in RIPA buffer via phosphatase (Applygen, P1260) and protease (Boster, AR0101/AR0103) inhibitors. The lysate received centrifugation at $12000 \mathrm{~g}$ for $20 \mathrm{~min}$, and cytosol proteins were extracted. Bicinchoninic acid (BCA) reagent determined the protein concentration. Proteins were isolated using 12-15\% SDS-PAGE before transfer on PVDF membranes. Thereafter, we blocked membranes using 5\% skimmed milk and cultured them using primary antibodies, including $p$-Akt $(1: 1000)$, Akt $(1: 1000)$, Nrf2 (1:1000), NQO1 (1:1000), HO-1 (1:1000), SOD2 $(1: 2000)$, CAT $(1: 1000), \operatorname{Bcl}-2(1: 1000)$, Bax $(1: 1000)$, and $\beta$-actin $(1: 10000)$, under $4^{\circ} \mathrm{C}$ overnight, followed by another $1 \mathrm{~h}$ horseradish peroxidase-conjugated-labeled secondary antibody incubation on the following day. Visualization for signals and band intensity was done with chemiluminescence in the gel imaging system (Bio-Rad Laboratories, Hercules, CA, USA).

2.7. Nrf2 siRNA Transfection. The siRNA targeting the Nrf2(sc-37030) was adopted for knocking down Nrf2 levels. We analyzed transfection efficiency using fluorescein-labeled control siRNA(sc-36869). HLECs were first seeded into a 6well plate, followed by incubation under $5 \% \mathrm{CO}_{2}$ and $37^{\circ} \mathrm{C}$ conditions till then reached $70-80 \%$ confluence. Then, in terms of each transfection, we diluted Nrf2 or control siRNA $(2 \mu \mathrm{L})$ and transfection reagent $(2 \mu \mathrm{L}, \mathrm{sc}-29528)$ in the siRNA transfection medium $(100 \mu \mathrm{L}$, sc-36868; Santa Cruz, CA, USA), separately. Then, we combined dilutions to incubate under ambient temperature for $0.5 \mathrm{~h}$. After that, cells were transfected for $12 \mathrm{~h}$ and subsequently treated with $50 \mu \mathrm{g} / \mathrm{mL} \mathrm{KGF}-2$ for $2 \mathrm{~h}$ before the treatment with $100 \mu \mathrm{M}$ $\mathrm{H}_{2} \mathrm{O}_{2}$ for $12 \mathrm{~h}$.

2.8. Lens Organ Culture and Treatment. Male SD rats were obtained from the Charles River (Beijing, China). The Institutional Animal Experimentation Ethics Committee of the Wenzhou Medical University approved all animal protocols in the current work. Rat eyes were firstly extracted and stored within the heated $\left(37^{\circ} \mathrm{C}\right)$ mammalian normal saline. We then cultured fresh transparent lenses within the medium that contained $0.1 \% \mathrm{BSA}$ and gentamicin $(50 \mathrm{mg} /$ $\mathrm{mL}$ ) under $5 \% \quad \mathrm{CO}_{2}$ and $37^{\circ} \mathrm{C}$ conditions. Lenses were treated with KGF-2 at the concentration of 50 and $100 \mu \mathrm{g} /$ $\mathrm{mL}$ for $2 \mathrm{~h}$ at $37^{\circ} \mathrm{C}$. Then, with the addition of $100 \mu \mathrm{M}$ $\mathrm{H}_{2} \mathrm{O}_{2}$ for $12 \mathrm{~h}$, lenses were detected via the stereomicroscope and shot in a black gridline background, thus recording the opacity development course. Further, lenses per group were rinsed in cold saline, placed on a filter paper for drying, dissected using Vannas scissors, and finally milled above the ice. Eventually, the tissue was spun down inside the refrigerated centrifuge at $1000 \mathrm{rpm}$ for $10 \mathrm{~min}$. Supernatants underwent lysis treatment above the ice for $20 \mathrm{~min}$ through radioimmunoprecipitation assay (RIPA) buffer with protease inhibitor cocktail and centrifugation at $12000 \mathrm{~g}$ for $20 \mathrm{~min}$. Variations of indicated protein expression levels were assessed through western blotting as described above.

2.9. Statistical Analysis. Data used in the current experiment were indicated by mean \pm SD. GraphPad Prism 6 (GraphPad Software, San Diego, CA, USA) was employed for statistical analyses. ANOVA was conducted to analyze significance. $p$ values below 0.05 suggested statistical significance.

\section{Results}

3.1. Effects of $\mathrm{H}_{2} \mathrm{O}_{2}$ and KGF-2 on HLEC's Viability. $\mathrm{H}_{2} \mathrm{O}_{2}$ damaged cell viability in a concentration and timedependent way (Figure $1(\mathrm{a})$ ). $100 \mu \mathrm{M} \mathrm{H}_{2} \mathrm{O}_{2}$ for $12 \mathrm{~h}$ was used in the following tests, which decreased cell viability to around $53.22 \pm 1.29 \%$ in comparison with controls (without $\mathrm{H}_{2} \mathrm{O}_{2}$ treatment). Treatment with a broad range of KGF-2 concentrations exerted no cytotoxic effects on HLECs (Figure 1(b)). Besides, HLECs pretreated by KGF-2 exhibited a concentration-dependent protective effect against $\mathrm{H}_{2} \mathrm{O}_{2}$ damage (Figure 1(c)).

3.2. KGF-2 Suppressed $\mathrm{H}_{2} \mathrm{O}_{2}$-Induced Apoptosis in HLECs. Bcl-2 protein family has a critical function in modulating the mitochondrial apoptotic pathway [32]. In addition, the caspase family exerts a crucial function in the initiation and execution of programmed cell death. As a kind of executioner caspase, caspase- 3 is activated within apoptotic cells via the internal and external (death ligand) pathways [33]. Therefore, members in the Bcl-2 family (either proapoptotic or antiapoptotic) and cleaved caspase- 3 can affect the performance of apoptosis. Western blotting analysis revealed that exposure to $\mathrm{H}_{2} \mathrm{O}_{2}$ enhanced $\mathrm{Bax}$ and cleaved caspase- 3 expression but reduced Bcl-2 expression in HLECs, whereas such effects could be eliminated through pretreatment with KGF-2 in a concentration-dependent manner (Figure 2(a)). Consistent with western blotting analysis, flow cytometry manifested that KGF-2 could relieve $\mathrm{H}_{2} \mathrm{O}_{2}$-induced viability decrease of HLECs (Figure 2(b)).

3.3. KGF-2 Inhibited $\mathrm{H}_{2} \mathrm{O}_{2}$-Induced Oxidative Stress in HLECs. HLECs exposed to $\mathrm{H}_{2} \mathrm{O}_{2}$ have a light green color after the incubation of the DCFH-DA reagent, indicating a 


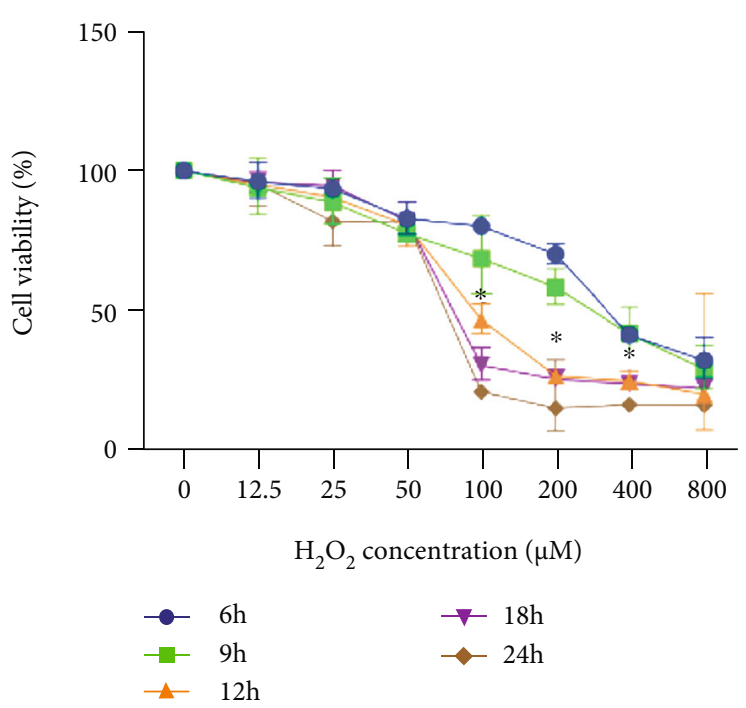

(a)

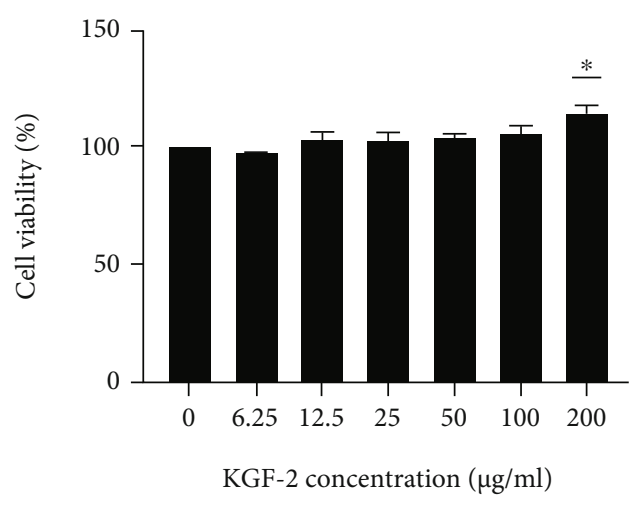

(b)

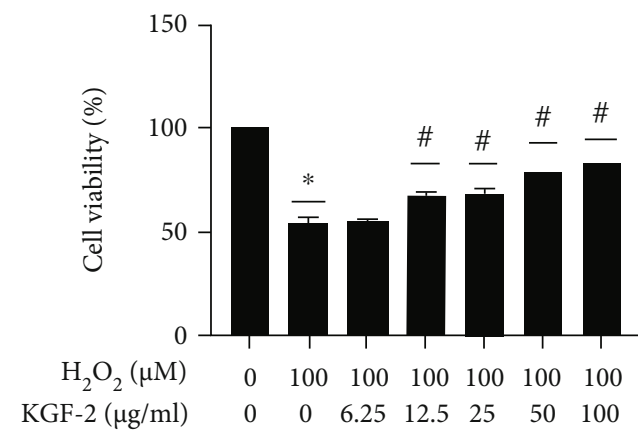

(c)

FIGURE 1: KGF-2 relieved $\mathrm{H}_{2} \mathrm{O}_{2}$-induced viability decrease in HLECs. (a) Exposure of HLECs to various concentrations of $\mathrm{H}_{2} \mathrm{O}_{2}$ at different time points and cell viability analysis through MTT assay on absorbance at $570 \mathrm{~nm} .{ }^{*} p<0.05$ vs. control group. (b) Cell viability evaluation through MTT assay following HLECs treated with KGF-2 at varying concentrations for $24 \mathrm{~h} .{ }^{*} p<0.05$ vs. control group. (c) Cell viability evaluation through MTT assay on HLECs pretreated using KGF- 2 for $2 \mathrm{~h}$, and $100 \mu \mathrm{M} \mathrm{H}_{2} \mathrm{O}_{2}$ was added for treatment for $12 \mathrm{~h}$. ${ }^{*} p<0.05$ vs. control group. $\# p<0.05$ vs. cell treated with $\mathrm{H}_{2} \mathrm{O}_{2}$ alone. Data are presented in a form of mean \pm SD from 3 separate assays.

prominent rise of ROS levels. Such rise could be avoided in a concentration-dependent way by pretreatment with KGF-2 (Figure 3(a)). Flow cytometry analyses reveal that $\mathrm{H}_{2} \mathrm{O}_{2}$ induction markedly elevated intracellular ROS production in comparison with control, while KGF-2 remarkably reduced it compared with $\mathrm{H}_{2} \mathrm{O}_{2}$-induced HLECs (Figure 3(b)). Furthermore, the antioxidant capacity of KGF-2 in $\mathrm{H}_{2} \mathrm{O}_{2}$-stimulated HLECs is assessed by measuring the levels of antioxidant enzymes (containing SOD2, NQO1, and CAT). $\mathrm{H}_{2} \mathrm{O}_{2}$ significantly reduces SOD2 and CAT activity and increases NQO-1 content relative to the control group. In comparison with the $\mathrm{H}_{2} \mathrm{O}_{2}$ group, KGF-2 pretreatment substantially increases SOD2 and CAT levels and further increases NQO-1 content (Figure 3(c)). These findings show that KGF-2 inhibits $\mathrm{H}_{2} \mathrm{O}_{2}$-induced oxidative damage of HLECs.

3.4. KGF-2 Treatment Reduces Oxidative Stress and Apoptosis by Activating the PI3K/Akt Pathway. KGF-2 facilitates multiple biological activities via paracrine through activating PI3K/Akt pathway [21, 34]. Western blotting analysis indicated KGF-2 significantly reinforced phosphorylation in Akt in a concentration-dependent manner (Figure 4(a)). In contrast, LY294002, an inhibitor for PI3K/ Akt, suppresses the Akt phosphorylation induced by KGF2 (Figure 4(b)). We also used LY294002 to verify if the PI3K/Akt pathway contributed to KGF-2-mediated cytoprotective effects. LY294002 could reverse the antiapoptotic effect of KGF-2 through increasing Bax and cleaved caspase- 3 content and decreasing Bcl-2 content compared with KGF-2 pretreatment (Figure 4(c)). Meanwhile, LY294002 attenuated KGF-2-induced increase of the activates of SOD2, CAT, and NQO-1 content in $\mathrm{H}_{2} \mathrm{O}_{2}$-stimulated HLECs (Figure 4(d)). These findings demonstrate that KGF-2 suppressed $\mathrm{H}_{2} \mathrm{O}_{2}$-induced apoptosis and oxidative stress of HLECs by eliciting the PI3K/Akt pathway.

3.5. KGF-2 Activates the Nrf2/HO-1 Signaling Pathway via the PI3K/Akt Pathway and Involves against $\mathrm{H}_{2} \mathrm{O}_{2}$-Induced Cytotoxicity. This study analyzed the effects of KGF-2 on the Nrf2/HO-1 pathway to explore the molecular mechanism further. The western blotting analysis demonstrates 

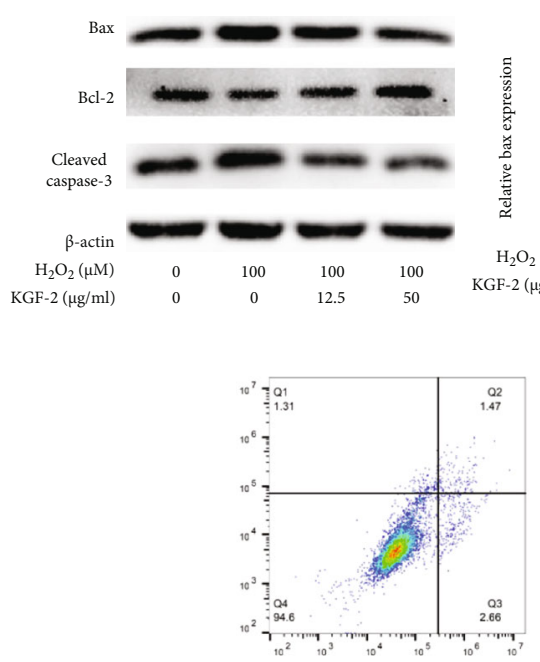

Control

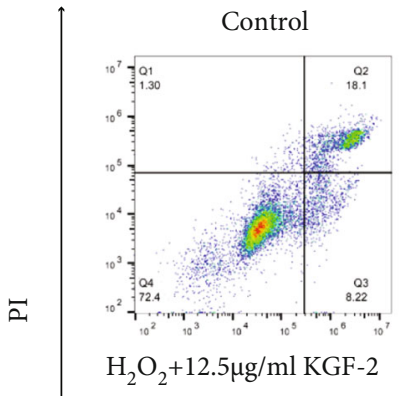

Annexin V-FITC
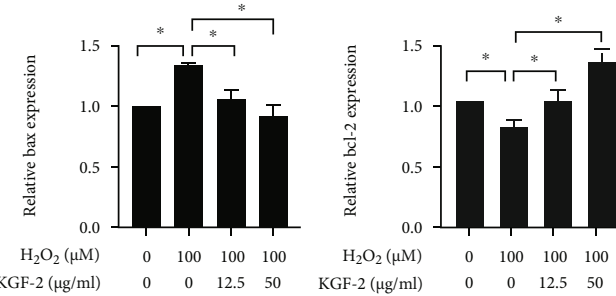

$\begin{array}{llllr}0 & 0 & 12.5 & 50 & \mathrm{KGF}-2(\mu \mathrm{g} / \mathrm{ml})\end{array}$

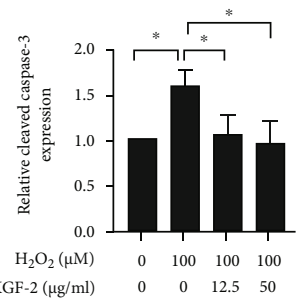

(a)

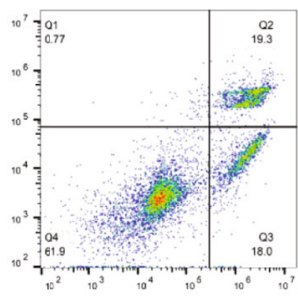

$\mathrm{H}_{2} \mathrm{O}_{2}$
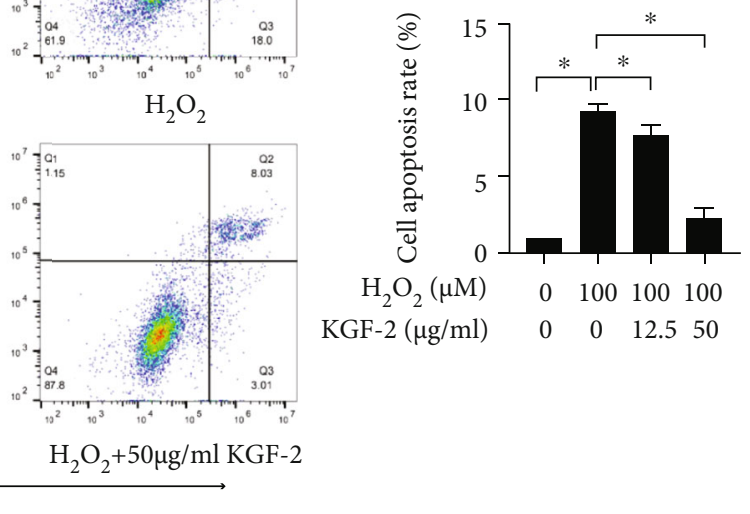

(b)

Figure 2: KGF-2 relieved $\mathrm{H}_{2} \mathrm{O}_{2}$-induced apoptosis in HLECs. (a) Protein level detection through western blotting analysis for Bax, Bcl-2, and cleaved caspase-3 of treated HLECs. (b) The proportion of apoptosis was measured by Annexin V-FITC and PI assays with flow cytometry. Data are presented in a form of mean \pm SD from 3 separate assays. ${ }^{*} p<0.05$.

that KGF-2 pretreatment efficiently promotes $\mathrm{Nrf2}$ and $\mathrm{HO}-$ 1 protein expression in comparison with the $\mathrm{H}_{2} \mathrm{O}_{2}$-stimulated HLECs (Figure 5(a)). Moreover, LY294002 can block Nrf2 and HO-1 protein expression induced by KGF-2 (Figure 5(b)), indicating that LY294002 significantly inhibits the cytoprotective effect of KGF-2.

To verify whether HO-1 and Nrf2 were required for the protective function of KGF-2, we pretreated HLECs with $\mathrm{ZnPP}$ and evaluated cell viability by MTT assays. ZnPP remarkably reversed the cytoprotective impacts of KGF-2 on $\mathrm{H}_{2} \mathrm{O}_{2}$-induced cytotoxicity (Figure 5(c)). Besides, Nrf2 siRNA has significantly weakened the cell viability in the HLECs pretreated by KGF-2 (Figure 5(d)). According to the obtained data, Nrf2 and HO-1 exert a crucial function in the cytoprotection regulated by KGF-2. Then, we studied the impacts of KGF-2 alone on Nrf2 and HO- 1 induction to verify if it is directly linked to both activations. HLECs treated with KGF-2 alone led to time-dependent induction in Nrf2 and HO-1 protein expression (Figure 5(e)). The Nrf2 siRNA treatment notably abolished the levels of HO1 expression regulated by KGF-2 in KGF-2-induced HLECs, suggesting that the upregulation of HO-1 is elicited by KGF2 mediation via Nrf2 activation (Figure 5(f)). Furthermore, we investigated the relationship between the Nrf2 and the $\mathrm{HO}-1$ handled by KGF-2 in $\mathrm{H}_{2} \mathrm{O}_{2}$-stimulated HLECs. Simi- larly, preincubation with Nrf2 siRNA markedly suppressed KGF-2-mediated upregulation of Nrf2 and HO-1 at the protein levels (Figure $5(\mathrm{~g})$ ). These findings support the fact that the cytoprotective effects of KGF-2 were mediated by the Nrf2/HO-1 pathway.

3.6. KGF-2 Prevents $\mathrm{H}_{2} \mathrm{O}_{2}$-Induced Lens Opacity. An organ culture experiment was performed to examine how KGF-2 affected cataractogenesis of rat lenses induced with $\mathrm{H}_{2} \mathrm{O}_{2}$. Morphological observational results verified transparency loss of lenses under exposure to $\mathrm{H}_{2} \mathrm{O}_{2}$. By contrast, untreated lenses showed almost no change. The opacities of rat lenses incubated in $\mathrm{H}_{2} \mathrm{O}_{2}$ media containing various concentrations of KGF-2 were analyzed and show remission in a KGF-2 concentration-dependent manner (Figure 6(a)). Western blotting measures Nrf2 and HO-1 level in $\mathrm{H}_{2} \mathrm{O}_{2}$ stimulated lens. Pretreatment with KGF-2 significantly increases the expression of Nrf2 and HO-1 (Figure 6(b)). Accordingly, KGF-2 blocked the process of cataractogenesis.

\section{Discussion}

Cataracts are the foremost cause of blindness globally, bringing serious socioeconomic crises to numerous countries. Unfortunately, there still lacks a well-received 


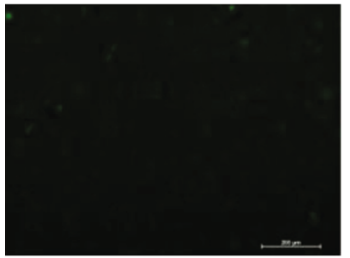

Control

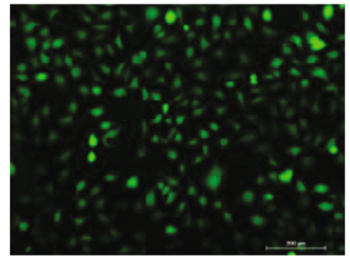

$\mathrm{H}_{2} \mathrm{O}_{2}$

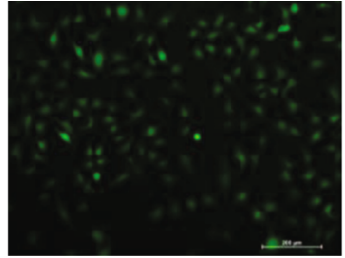

$\mathrm{H}_{2} \mathrm{O}_{2}+12.5 \mu \mathrm{g} / \mathrm{ml} \mathrm{KGF-2}$

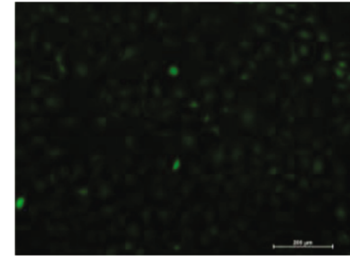

$\mathrm{H}_{2} \mathrm{O}_{2}+50 \mu \mathrm{g} / \mathrm{ml} \mathrm{KGF-2}$

(a)

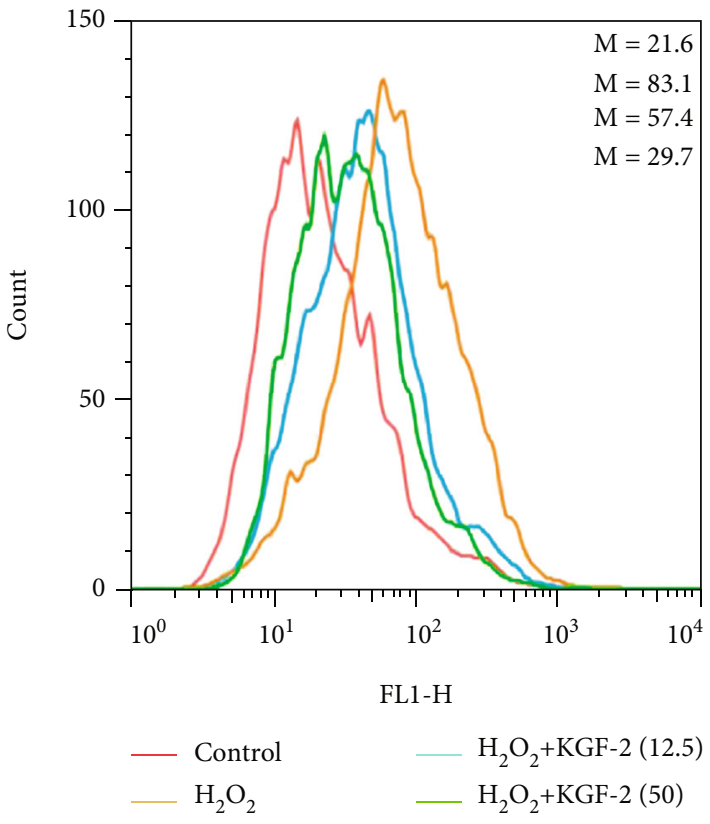

(b)

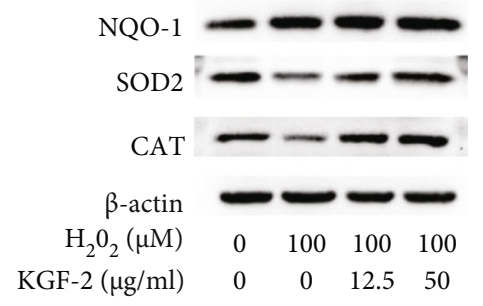

$\mathrm{KGF}-2(\mu \mathrm{g} / \mathrm{ml})$
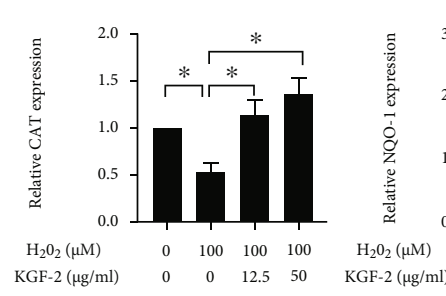

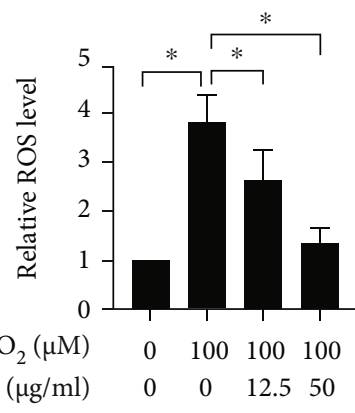

$\begin{array}{rcccc}\mathrm{H}_{2} \mathrm{O}_{2}(\mu \mathrm{M}) & 0 & 100 & 100 & 100 \\ \mathrm{KGF}-2(\mu \mathrm{g} / \mathrm{ml}) & 0 & 0 & 12.5 & 50\end{array}$

(c)

Figure 3: KGF-2 hindered $\mathrm{H}_{2} \mathrm{O}_{2}$-induced oxidative stress of HLECs. HLECs were treated with 12.5 and $50 \mu \mathrm{g} / \mathrm{mL}$ KGF-2 for $2 \mathrm{~h}$ before incubation with $100 \mu \mathrm{M} \mathrm{H}_{2} \mathrm{O}_{2}$ for $12 \mathrm{~h}$. (a) ROS production was measured with $10 \mu \mathrm{M}$ DCFH-DA after treatment of the cells. The morphological characteristics in the cell were analyzed under fluorescence microscopy. (b) ROS production was examined by flow cytometry. (c) NQO-1, SOD2, and CAT protein levels could be observed through western blotting analysis. Results are presented in a form of mean $\pm \mathrm{SD}$ from 3 separate assays. ${ }^{*} p<0.05$.

pharmacological agent to suppress opacification. Oxidative stress, characterized by excessive ROS, is an essential mediator of both the initiation and the progression of cataracts. Excessive production of ROS may disrupt oxidationantioxidant balance and cause mitochondrial dysfunction, lipid peroxidation, or cell apoptosis. Thus, decreasing oxidative stress and avoiding oxidative stress-induced apoptosis are likely therapeutic targets for cataracts [35].

KGF-2, a typical paracrine growth factor, signals using the interaction with its high-affinity receptor FGFR2-IIIb splicing isoform [36]. KGF-2 has numerous biological functions, including regulating cell survival and proliferation, suppressing inflammation, or exhibiting antioxidant effects. The exogenous supplementation of KGF-2 prevents the formation and development of multiple illnesses, such as wound healing defects, cardiovascular diseases, and metabolism syndrome, as well as acute kidney injury [18, 37-39]. For example, KGF-2 encourages axonal regeneration and functional recovery following peripheral nerve injury through protecting Schwann cells against excessive oxidative stress-induced apoptosis [23]. Our study reveals that KGF-2 exhibits no apparent cytotoxicity in HLECs. Given its nontoxic properties and favorable antioxidative effects, using KGF-2 to treat age-related cataracts may be an effective way. 


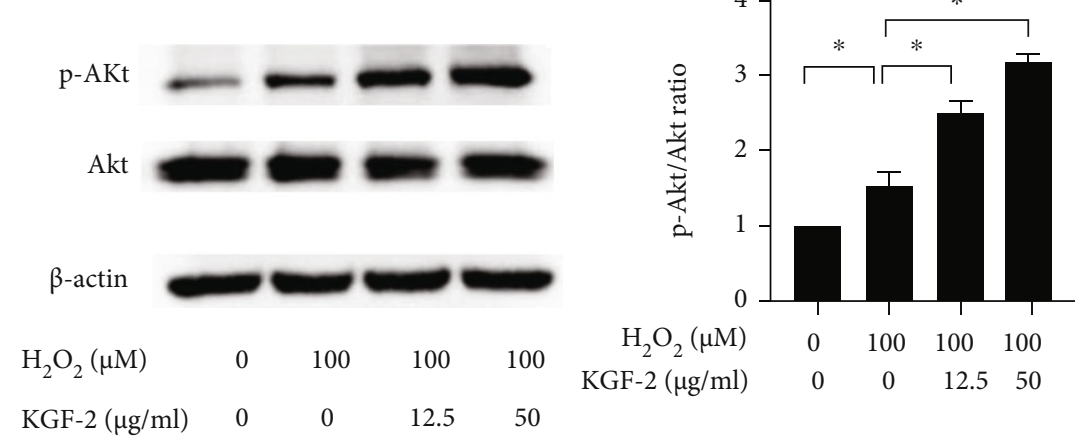

(a)

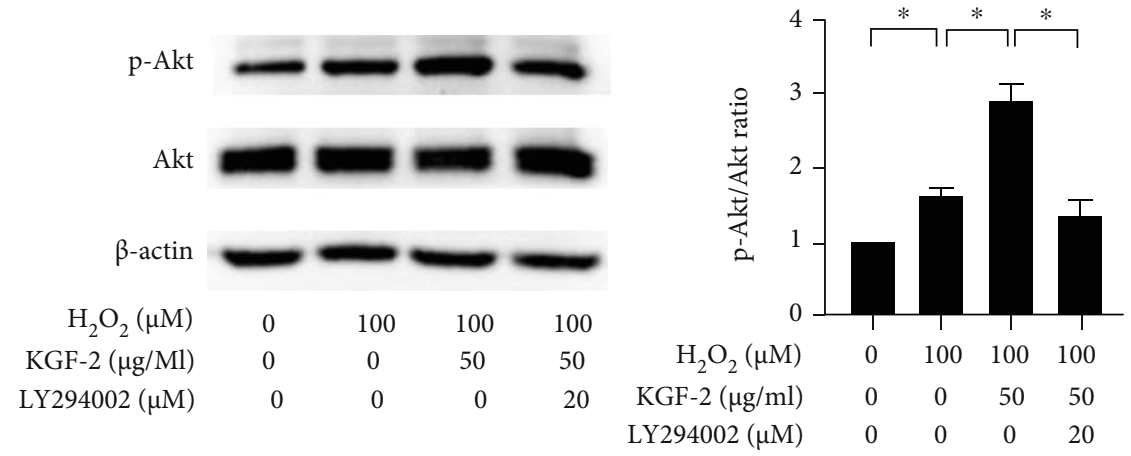

(b)
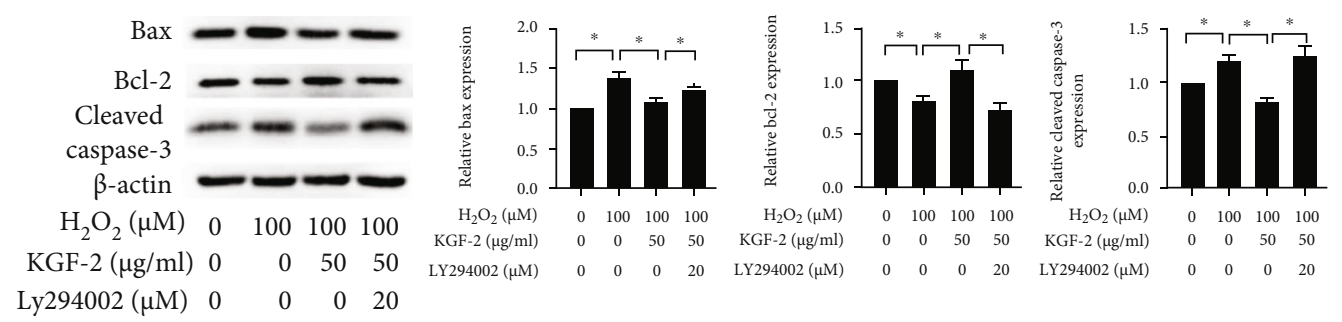

(c)
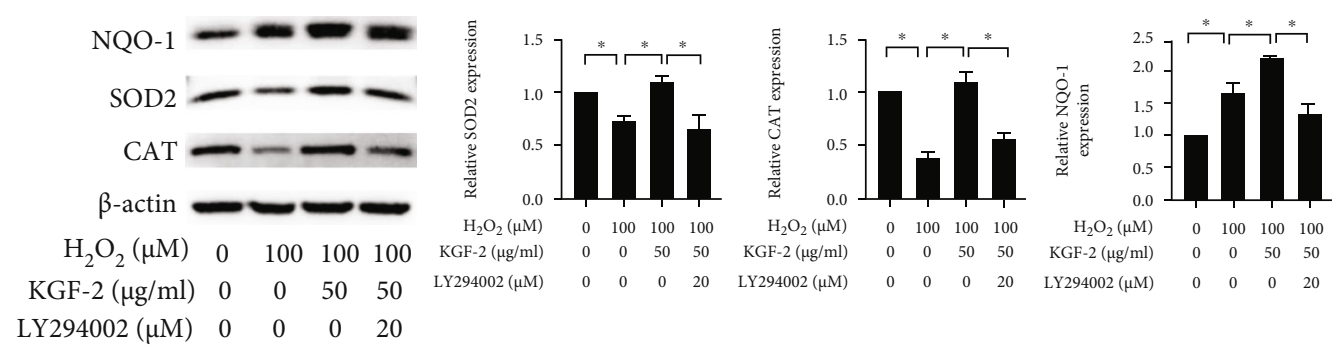

(d)

FIgURE 4: KGF-2 inhibited $\mathrm{H}_{2} \mathrm{O}_{2}$-induced apoptosis and oxidative stress by eliciting the PI3K/Akt pathway. HLECs were treated with or without KGF-2 for $2 \mathrm{~h}$ and were subsequently added with $100 \mu \mathrm{M} \mathrm{H}_{2} \mathrm{O}_{2}$ for $12 \mathrm{~h}$. (a) p-Akt and Akt protein levels of treated HLECs were measured through western blotting. Before adding KGF-2 and $\mathrm{H}_{2} \mathrm{O}_{2}$, HLECs were pretreated with $20 \mu \mathrm{M}$ LY294002 for $2 \mathrm{~h}$. (b) Western blotting analysis quantified Akt and p-Akt levels. (c) Western blotting analysis quantified cleaved caspase-3, Bcl-2, and Bax levels. (d) Western blotting analysis quantified NQO-1, CAT, and SOD2 levels. Results are presented in a form of mean \pm SD from 3 separate assays. ${ }^{*} p<0.05$.

$\mathrm{H}_{2} \mathrm{O}_{2}$, as an essential component in ROS, can accumulate considerably in both lens and aqueous humor [6]. Evidence had demonstrated the role of $\mathrm{H}_{2} \mathrm{O}_{2}$ in triggering HLECs apoptosis, causing the initiation of cataract formation [40]. The research showed exposure to concentration- dependent $\mathrm{H}_{2} \mathrm{O}_{2}$ decreased cell viability of HLECs, indicating $\mathrm{H}_{2} \mathrm{O}_{2}$ cytotoxicity against HLECs. However, pretreatment with KGF-2 relieved $\mathrm{H}_{2} \mathrm{O}_{2}$-induced decrease of HLEC viability and meantime prohibited apoptosis of HLECs induced by $\mathrm{H}_{2} \mathrm{O}_{2}$. Bcl-2, Bax, and cleaved caspase- 


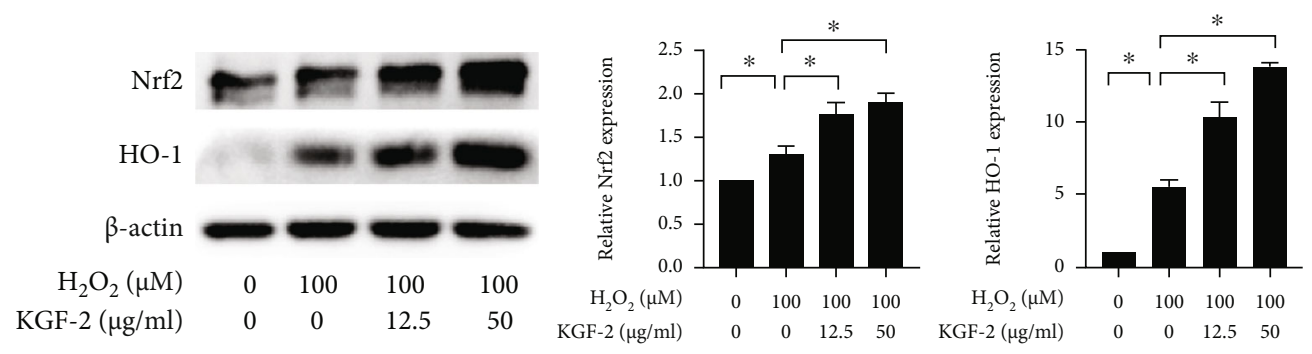

(a)

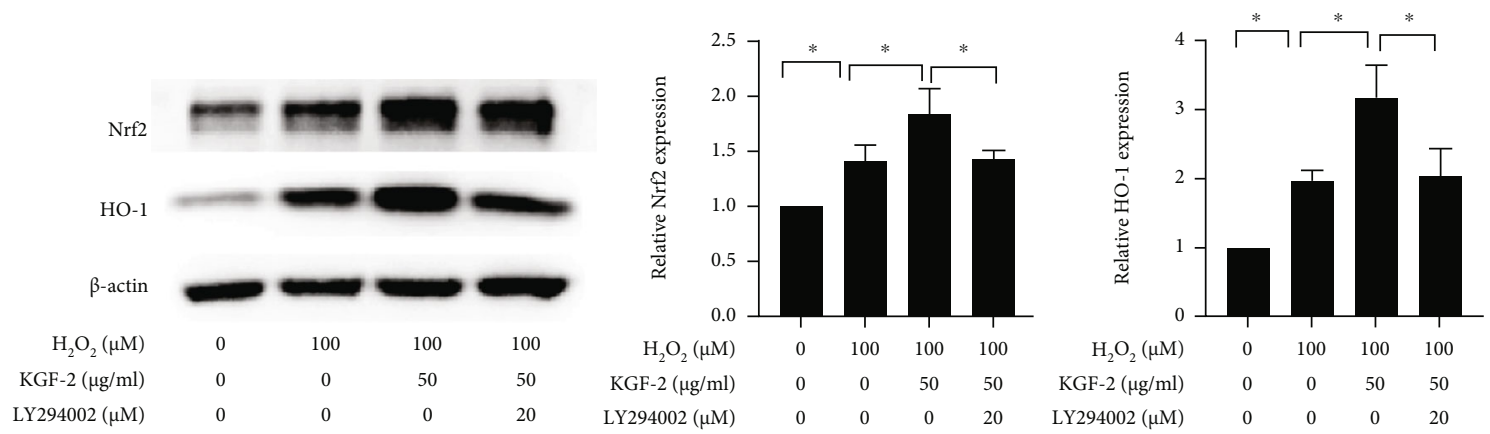

(b)

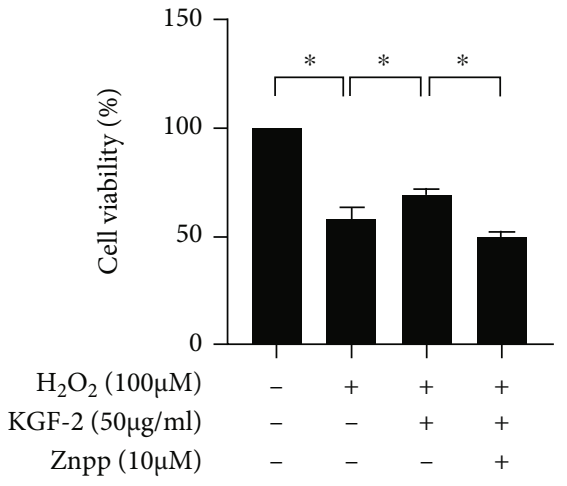

(c)

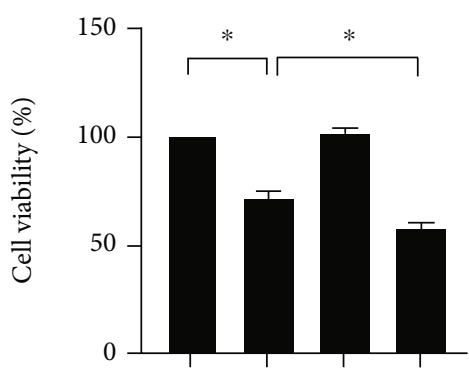

$\mathrm{H}_{2} \mathrm{O}_{2}(100 \mu \mathrm{M})$ KGF-2 $(50 \mu \mathrm{g} / \mathrm{ml})$

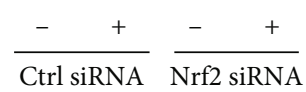

(d)
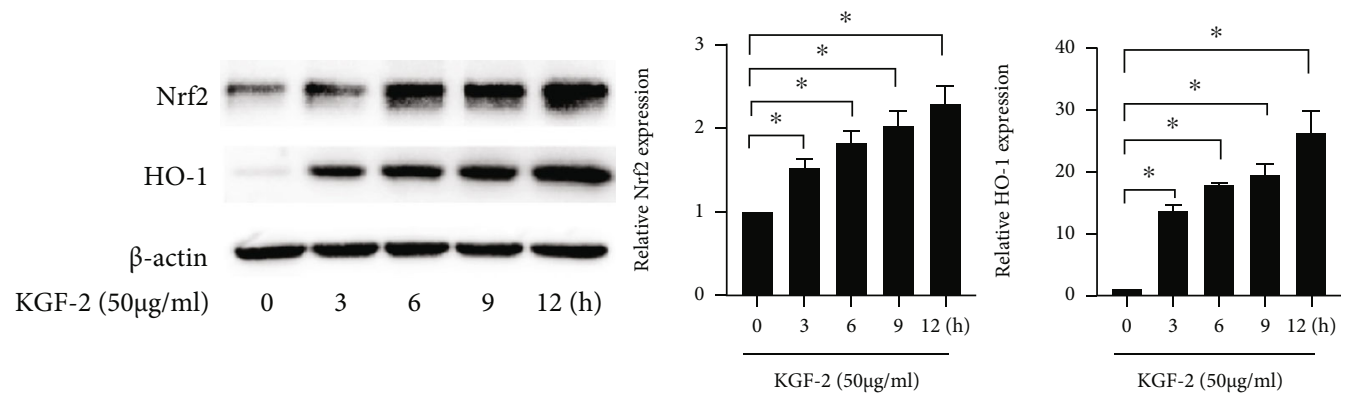

(e)

Figure 5: Continued. 

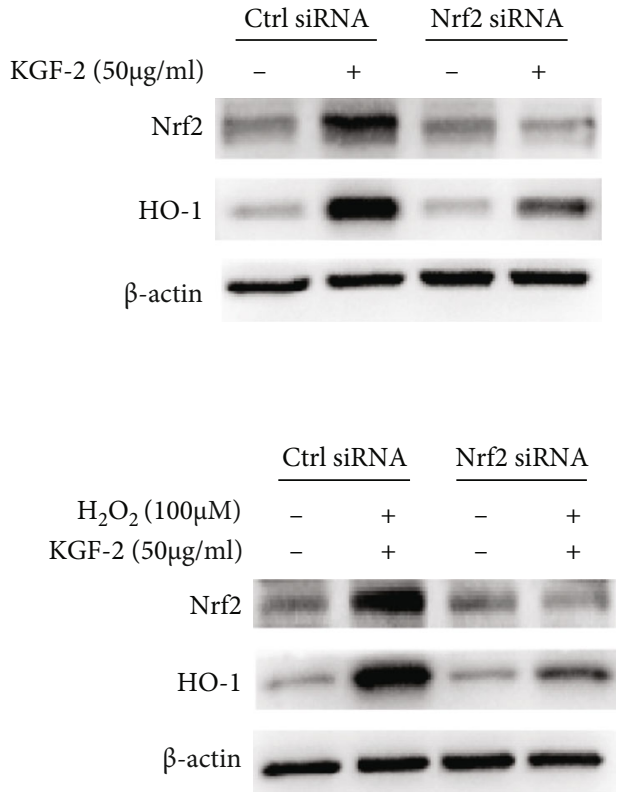

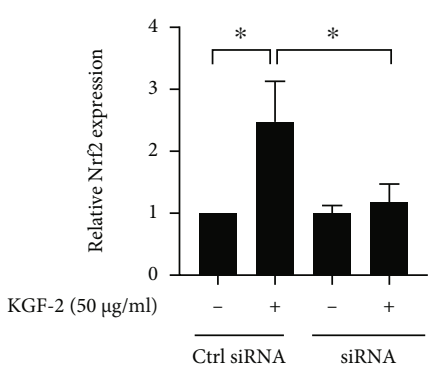

(f)

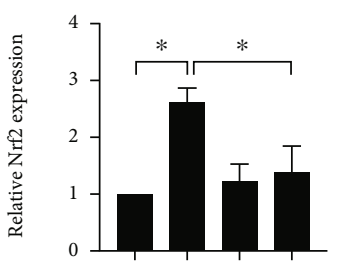

$\mathrm{H}_{2} \mathrm{O}_{2}(100 \mu \mathrm{M})$ $\mathrm{KGF}-2(50 \mu \mathrm{g} / \mathrm{ml})$

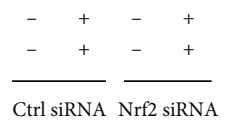

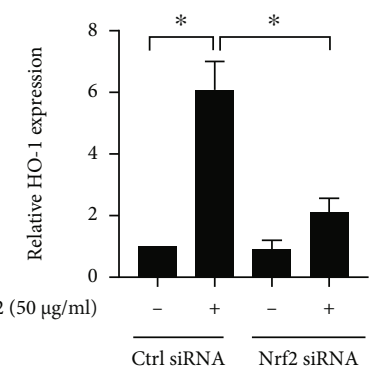

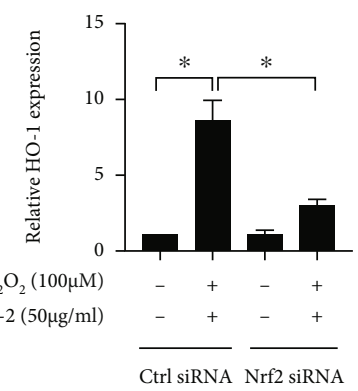

(g)

Figure 5: KGF-2 affects Nrf2 and HO-1 levels by the PI3K/Akt pathway and demonstrates cytoprotective effects via the Nrf2/HO-1 pathway. (a) HLECs were pretreated with or without KGF-2 for $2 \mathrm{~h}$, followed by $\mathrm{H}_{2} \mathrm{O}_{2}$ treatment for $12 \mathrm{~h}$. Western blotting analysis quantified Nrf2 and HO-1 levels. (b-d) HLECs were pretreated with $20 \mu \mathrm{M}$ LY294002 for $2 \mathrm{~h}$ or $10 \mu \mathrm{M}$ ZnPP for 30 min or Nrf2 siRNA for $12 \mathrm{~h}$, followed by $2 \mathrm{~h}$ treatment with KGF-2 and further $12 \mathrm{~h}$ treatment with $\mathrm{H}_{2} \mathrm{O}_{2}$. Western blotting analysis quantified Nrf2 and HO-1 levels, and MTT assay evaluated cell viability. (e) HLECs were pretreated with KGF-2 alone at different times. (f) HLECs were subject to $12 \mathrm{~h}$ transient transfection by Nrf2 siRNA and then $12 \mathrm{~h}$ KGF-2 treatment. (g) HLECs were subjected to $12 \mathrm{~h}$ transient transfection using Nrf2 siRNA, then $2 \mathrm{~h} \mathrm{KGF-2} \mathrm{treatment,} \mathrm{and} 12 \mathrm{~h} \mathrm{H}_{2} \mathrm{O}_{2}$ treatment. Western blotting analysis quantified Nrf2 and HO1 levels. Results are presented in a form of mean \pm SD from 3 separate assays. ${ }^{*} p<0.05$.

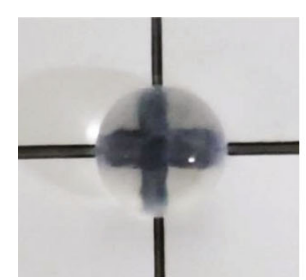

Control

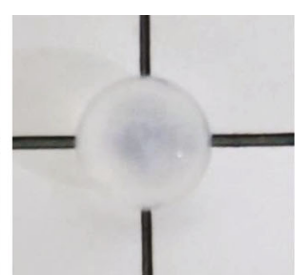

$\mathrm{H}_{2} \mathrm{O}_{2}$

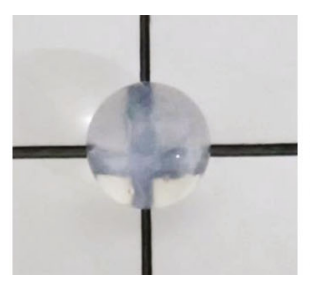

$\mathrm{H}_{2} \mathrm{O}_{2}+50 \mu \mathrm{g} / \mathrm{ml} \mathrm{KGF-2}$

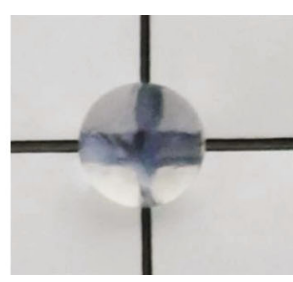

$\mathrm{H}_{2} \mathrm{O}_{2}+100 \mu \mathrm{g} / \mathrm{ml} \mathrm{KGF}-2$

(a)
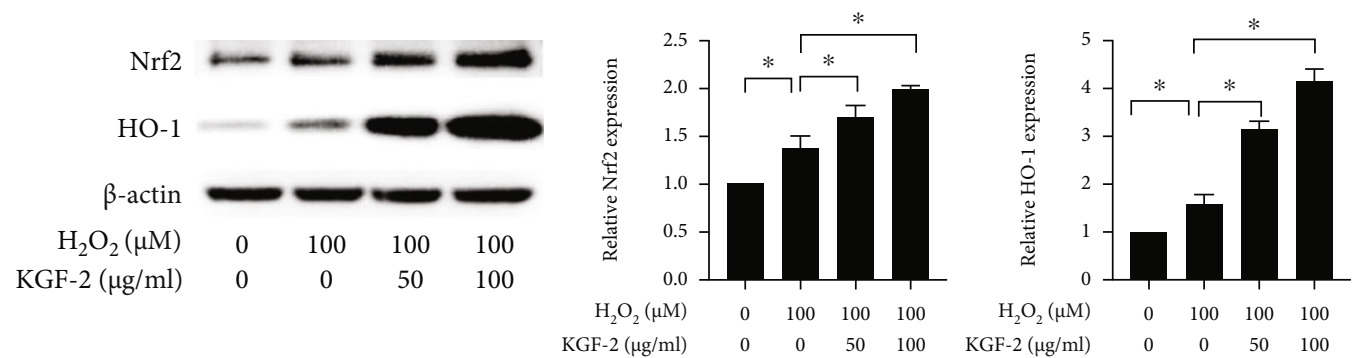

(b)

FIGURE 6: Effect of KGF-2 on lens organ incubate. (a) Effects of KGF-2 on the transparency of $\mathrm{H}_{2} \mathrm{O}_{2}$-induced rat lens. (b) Measurement of protein levels in lenses of Nrf2 and HO-1 using the western blotting analyses. Results are presented in a form of mean \pm SD from 3 separate assays. ${ }^{*} p<0.05$. 
3's proteins have been considered the foremost regulators of apoptosis. Bax is a proapoptotic gene, while Bcl-2 belongs to an antiapoptotic gene [41]. Caspase- 3 is the most used target to detect apoptosis [42]. $\mathrm{H}_{2} \mathrm{O}_{2}$ leads to $\mathrm{Bcl}-2$ downregulation whereas Bax and cleaved caspase- 3 upregulation, but the downregulation of $\mathrm{Bcl}-2$ and the upregulation of $\mathrm{Bax}$ and cleaved caspase- 3 were reversed after treatment with different concentrations of KGF-2. Besides, data indicate that KGF-2 has no cytotoxicity on HLECs. In general, KGF-2 exerts cytoprotective effects through ameliorating cell viability and blocking apoptosis of oxidative stress-stimulated HLECs.

Intracellular ROS is an indicator that reflects the level of oxidative stress directly. Hence, effects of KGF-2 on $\mathrm{H}_{2} \mathrm{O}_{2}$ induced intracellular ROS using the flow cytometry technique were detected. The results revealed that KGF-2 inhibits intracellular ROS production, showing the obvious antioxidative effects of KGF-2. In the meantime, our studies also showed an enhancement in the endogenous antioxidant systems with KGF-2 treatment. The antioxidant systems include numerous antioxidant enzymes including SOD2, CAT, and NQO-1, protecting cells from oxidative impairment following oxidative insult or during physiological metabolism. The three enzymes are indispensable to normal lens metabolism, which protect the lens against oxidative stress and retain lens transparency [43, 44]. $\mathrm{H}_{2} \mathrm{O}_{2}$-induced cataracts were linked to reduced SOD2 and CAT activities and reinforced NQO-1 activity of the lens. These changes were facilitated by KGF-2 at varying concentrations, proving that KGF-2 has the function of alleviating oxidative stress through increasing endogenous antioxidants.

The PI3K/Akt pathway provides a critical pathway cascade for promoting cell survival and inhibiting apoptosis. Furthermore, research shows that activation via the PI3K/ Akt pathway promotes the antioxidant defense ability of HLECs [45]. Considering that PI3K/Akt pathway has an essential effect on preventing cell stress and enhancing cell survival, it is speculated that this pathway is probably the critical pathway for KGF-2 to exert its cytoprotective effect. In our study, KGF-2 remarkably promoted phosphorylation in Akt subject to oxidative stress conditions, indicating that KGF-2 elicited the PI3K/Akt pathway to resist oxidative stress and retain cell survival. For deepening existing research on PI3K/Akt pathway and its protective effects on KGF-2 against $\mathrm{H}_{2} \mathrm{O}_{2}$-induced HLEC injury, LY294002, a pharmacological inhibitor of PI3K/Akt pathway engaged with the cytoprotective effects of KGF-2, was studied. LY294002 reversed the change of the antioxidant enzymes (SOD2, CAT, and NQO-1) and the apoptotic regulators (Bcl-2, Bax, and cleaved caspase-3) induced by KGF-2 in the $\mathrm{H}_{2} \mathrm{O}_{2}$-stimulated HLECs. It also significantly decreased SOD2, CAT, and Bcl-2 expression and increased NQO-1, Bax, and cleaved caspase-3 expression, demonstrating PI3K/Akt pathway's involvement in cytoprotective effects on KGF-2.

It is universally believed that Nrf2 is a significant transcription factor that plays an indispensable role in the expression of antioxidant and detoxification enzymes. HO1, a famous phase II detoxifying enzyme, can considerably balance redox homeostasis and inhibit inflammatory illnesses [46, 47]. In oxidative stress, HO-1 undergoes upregulation to reinforce the cellular defense mechanism against oxidative insult [48-50]. PI3K/Akt pathway is found to exert a cytoprotective influence by enhancing the Nrf2/HO-1 pathway [51-54]. Data shows that KGF-2 pretreatment effectively increases the expression of Nrf2 and HO-1 in $\mathrm{H}_{2} \mathrm{O}_{2}$-stimulated HLECs. However, this increase was significantly downregulated by LY294002, indicating the partial involvement of the PI3K/Akt pathway in activating the $\mathrm{Nrf} 2$ and HO-1. An interesting finding is that $\mathrm{ZnPP}$ and Nrf2 siRNA abolishes the KGF-2's protective effect against $\mathrm{H}_{2} \mathrm{O}_{2}$-induced HLEC death, indicating that Nrf2 and HO1 are essential in KGF-2-induced cytoprotection. Besides, Nrf2 belongs to an upstream mediator of phase II detoxifying enzymes; thus, Nrf2 translocation can mediate HO-1 gene transcription for enhancing cellular defensive capacity and combating oxidative stress $[55,56]$. We evaluated the effect of KGF-2 alone on Nrf2 and HO-1 to further demonstrate that KGF-2 participates in the activation of a cytoprotective pathway. The results demonstrated that KGF-2 activates HO-1 and Nrf2 levels depending on time. When we knock down the expression of Nrf2 using Nrf2 siRNA, the content of HO-1 is also reduced. We further determine the impact of KGF-2 on the expression of Nrf2 and HO-1 protein in $\mathrm{H}_{2} \mathrm{O}_{2}$-induced HLECs. Similarly, Nrf2 siRNA abolished this enhancement in Nrf2 and HO-1 induced by KGF-2 in $\mathrm{H}_{2} \mathrm{O}_{2}$-stimulated HLECs, suggesting the cytoprotective effect of KGF-2 in regard to the Nrf2/HO-1 pathway. Therefore, these findings provide direct evidence that the Nrf2/HO-1 pathway regulated by KGF-2 may be an underlying therapeutic target for cataracts.

The in vitro experiments confirmed the effects of KGF2 on the prevention of oxidative stress-induced cell apoptosis, whereas the key to the problem is whether KGF-2 is efficient in lens tissue. For answering the question, we refer to the findings in an ex vivo experiment evaluating KGF-2's anticataract potential of $\mathrm{H}_{2} \mathrm{O}_{2}$-mediated rat lens isolation through monitoring the lens transparency while predicting several biochemical variables like Nrf2 and HO-1 contents. Compared with the normal lenses, the transparency of the lens exposed to $\mathrm{H}_{2} \mathrm{O}_{2}$ in vitro was decreased. However, the $\mathrm{H}_{2} \mathrm{O}_{2}$-induced opacity of lenses was ameliorated by treatment using KGF-2. Therefore, results in relevant ex vivo experiments suggest that KGF2 effectively stunted $\mathrm{H}_{2} \mathrm{O}_{2}$-induced cataract formation, possibly by increasing the contents of Nrf2 and HO- 1 to maintain the lens transparency.

In conclusion, this study confirmed the ability of $\mathrm{H}_{2} \mathrm{O}_{2}$ in inducing HLEC apoptosis and lens opacification, while KGF-2 may efficiently alleviate lens opacity and the apoptosis of human lens epithelial cells under $\mathrm{H}_{2} \mathrm{O}_{2}$-induced oxidative stress. Furthermore, KGF-2, an effective antioxidant, was found to be efficiently protect HLECs through PI3K/ Akt and Nrf2/HO-1 signaling pathways (see supplementary materials (available here)). Also, the safety of KGF-2 in intraocular use has been confirmed; we believed that KGF2 can be applied in clinical practice as an underlying protective agent in cataract formation. 


\section{Data Availability}

All data included in this study are available upon request by contact with the corresponding author.

\section{Conflicts of Interest}

The authors declare that they have no conflicts of interest.

\section{Authors' Contributions}

SL and ZJ carried out the studies and collected data. RX and ZZ performed the data analysis and participated in article writing. YZ and XW helped to search the literature and revise the article. QW designed the experiments and provided the samples for the study. HY and JC designed the study and wrote the manuscript. SL and ZJ contributed equally to this work. Shuyu Liu and $\mathrm{Zi}$ Jin contributed equally to this work and share first authorship.

\section{Acknowledgments}

This study was supported by the Natural Science Foundation of Zhejiang Province (Grant Nos. LY17H300003 and GD21H120004) and the National Natural Science Foundation of China (Grant No. 81600759).

\section{Supplementary Materials}

A schematic diagram of the pathway by which KGF-2 protected HLECs from $\mathrm{H}_{2} \mathrm{O}_{2}$-induced oxidative stress. (Supplementary Materials)

\section{References}

[1] D. Pascolini and S. P. Mariotti, "Global estimates of visual impairment: 2010," The British Journal of Ophthalmology, vol. 96, no. 5, pp. 614-618, 2012.

[2] J. M. Petrash, "Aging and age-related diseases of the ocular lens and vitreous body," Investigative Ophthalmology \& Visual Science, vol. 54, no. 14, pp. ORSF54-ORSF59, 2013.

[3] S. C. Manolagas and M. Almeida, "Gone with the Wnts: betacatenin, $\mathrm{T}$-cell factor, forkhead box $\mathrm{O}$, and oxidative stress in age-dependent diseases of bone, lipid, and glucose metabolism," Molecular Endocrinology, vol. 21, no. 11, pp. 26052614, 2007.

[4] T. Finkel and N. Holbrook, "Oxidants, oxidative stress and the biology of ageing," Nature, vol. 408, no. 6809, pp. 239-247, 2000.

[5] W.-C. Li and R. Jerome, "Lens epithelial cell apoptosis appears to be a common cellular basis for non-congenital cataract development in humans and animals," Journal of Cell Biology, vol. 130, no. 1, pp. 169-181, 1995.

[6] S. Csukas, A. Costarides, M. V. Riley, and K. Greent, "Hydrogen peroxide in the rabbit anterior chamber: effects on glutathione, and catalase effects on peroxide kinetics," Current Eye Research, vol. 6, no. 12, pp. 1395-1402, 1987.

[7] A. Spector, W. Ma, F. Sun, D. Li, and N. J. Kleiman, "The effect of $\mathrm{H} 2 \mathrm{O} 2$ and tertiary butyl hydroperoxide upon a murine immortal lens epithelial cell line, $\alpha \mathrm{TN} 4-1$," Experimental Eye Research, vol. 75, no. 5, pp. 573-582, 2002.
[8] A. Spector and W. Garner, "Hydrogen peroxide and human cataract," Experimental Eye Research, vol. 33, no. 6, pp. 673681, 1981.

[9] R. Wei, R. Ding, L. Tang, and Y. Wang, "Grape seed proanthocyanidin extract reduces renal ischemia/reperfusion injuries in rats," The American Journal of the Medical Sciences, vol. 343, no. 6, pp. 452-457, 2012.

[10] X. Tang, K. Yao, L. Zhang, Y. Yang, and H. Yao, "Honokiol inhibits $\mathrm{H} 2 \mathrm{O} 2$-induced apoptosis in human lens epithelial cells via inhibition of the mitogen-activated protein kinase and Akt pathways," European Journal of Pharmacology, vol. 650, no. 1, pp. 72-78, 2011.

[11] J. Yang, L. Cai, S. Zhang, X. Zhu, P. Zhou, and Y. Lu, "Silica-based cerium (III) chloride nanoparticles prevent the fructose-induced glycation of $\alpha$-crystallin and $\mathrm{H} 2 \mathrm{O} 2$ induced oxidative stress in human lens epithelial cells," Archives of Pharmacal Research, vol. 37, no. 3, pp. 404411, 2014.

[12] H. Y. Koo, L. M. El-Baz, S. House et al., "Fibroblast growth factor 2 decreases bleomycin-induced pulmonary fibrosis and inhibits fibroblast collagen production and myofibroblast differentiation," The Journal of Pathology, vol. 246, no. 1, pp. 54-66, 2018.

[13] M. I. Takeoka, W. F. Ward, H. Pollack, D. W. Kamp, and R. J. Panos, "KGF facilitates repair of radiation-induced DNA damage in alveolar epithelial cells," The American Journal of Physiology, vol. 272, 6 Part 1, p. L1174, 1997.

[14] K. Wu and R. J. Panos, "Keratinocyte growth factor promotes alveolar epithelial cell DNA repair after $\mathrm{H} 2 \mathrm{O} 2$ exposure," American Journal of Physiology, vol. 275, no. 4, pp. L780L787, 1998.

[15] L. Ware and M. Matthay, "Keratinocyte and hepatocyte growth factors in the lung: roles in lung development, inflammation, and repair," American Journal of Physiology Lung Cellular and Molecular Physiology, vol. 282, no. 5, pp. L924-L940, 2002.

[16] H. Ohuchi, "Wakayama symposium: epithelial-mesenchymal interactions in eyelid development," The Ocular Surface, vol. 10, no. 4, pp. 212-216, 2012.

[17] M. Prochazkova, J. Prochazka, P. Marangoni, and O. D. Klein, "Bones, glands, ears and more: the multiple roles of FGF10 in craniofacial development," Frontiers in Genetics, vol. 9, p. 542, 2018.

[18] X. Tan, H. Zhu, Q. Tao et al., "FGF10 protects against renal ischemia/reperfusion injury by regulating autophagy and inflammatory signaling," vol. 9, p. 556, 2018.

[19] X. Tan, L. Yu, R. Yang et al., "Fibroblast growth factor 10 attenuates renal damage by regulating endoplasmic reticulum stress after ischemia-reperfusion injury," Frontiers in Pharmacology, vol. 11, p. 39, 2020.

[20] D. Upadhyay, M. Bundesmann, V. Panduri, E. Correa-Meyer, and D. W. Kamp, "Fibroblast growth factor-10 attenuates $\mathrm{H} 2 \mathrm{O} 2$-induced alveolar epithelial cell DNA damage," American Journal of Respiratory Cell and Molecular Biology, vol. 31, no. 1, pp. 107-113, 2004.

[21] J. Chen, Z. Wang, Z. M. Zheng et al., "Neuron and microglia/ macrophage-derived FGF10 activate neuronal FGFR2/PI3K/ Akt signaling and inhibit microglia/macrophages TLR4/NF$\kappa \mathrm{B}$-dependent neuroinflammation to improve functional recovery after spinal cord injury," Cell Death \& Disease, vol. 8, no. 10, article e3090, 2017. 
[22] J. Cai, W. Li, J. Li et al., "Toxicology study of long-term administration of rhKGF-2 eye drops on rabbit corneas," Regulatory Toxicology and Pharmacology, vol. 103, pp. 189-195, 2019.

[23] L. Dong, R. Li, D. Li et al., "FGF10 enhances peripheral nerve regeneration via the preactivation of the PI3K/Akt signalingmediated antioxidant response," Frontiers in Pharmacology, vol. 10, p. 1224, 2019.

[24] J. Watson and C. Francavilla, "Regulation of FGF10 signaling in development and disease," Frontiers in Genetics, vol. 9, p. $500,2018$.

[25] D. A. Fruman, H. Chiu, B. D. Hopkins, S. Bagrodia, L. C. Cantley, and R. T. Abraham, "The PI3K pathway in human disease," Cell, vol. 170, no. 4, pp. 605-635, 2017.

[26] J. Xu, D. Li, Y. Lu, and T. Y. Zheng, “A $\beta$ monomers protect lens epithelial cells against oxidative stress by upregulating CDC25B," Free Radical Biology \& Medicine, vol. 175, pp. 161-170, 2021.

[27] X. Hu, Y. Liang, B. Zhao, and Y. Wang, "Oxyresveratrol protects human lens epithelial cells against hydrogen peroxideinduced oxidative stress and apoptosis by activation of Akt/ HO-1 pathway," Journal of Pharmacological Sciences, vol. 139, no. 3, pp. 166-173, 2019.

[28] N. Wakabayashi, S. L. Slocum, J. J. Skoko, S. Shin, and T. W. Kensler, "When NRF2 talks, who's listening?," Antioxidants \& Redox Signaling, vol. 13, no. 11, pp. 1649-1663, 2010.

[29] H. K. Bryan, A. Olayanju, C. E. Goldring, and B. K. Park, "The Nrf2 cell defence pathway: Keap1-dependent and -independent mechanisms of regulation," Biochemical Pharmacology, vol. 85, no. 6, pp. 705-717, 2013.

[30] Y. Gao, Y. Yan, and T. Huang, "Human agerelated cataracts: epigenetic suppression of the nuclear factor erythroid 2related factor 2mediated antioxidant system," Molecular Medicine Reports, vol. 11, no. 2, pp. 1442-1447, 2015.

[31] X.-F. Liu, J.-L. Hao, T. Xie et al., "Nrf2 as a target for prevention of age-related and diabetic cataracts by against oxidative stress," Aging Cell, vol. 16, no. 5, pp. 934-942, 2017.

[32] B. Leibowitz and J. Yu, "Mitochondrial signaling in cell death via the Bcl-2 family," Cancer Biology \& Therapy, vol. 9, no. 6, pp. 417-422, 2010.

[33] S. Ghavami, M. Hashemi, S. R. Ande et al., "Apoptosis and cancer: mutations within caspase genes," Journal of Medical Genetics, vol. 46, no. 8, pp. 497-510, 2009.

[34] Y.-H. Li, H.-L. Fu, M.-L. Tian et al., "Neuron-derived FGF10 ameliorates cerebral ischemia injury via inhibiting NF- $\kappa \mathrm{B}$ dependent neuroinflammation and activating PI3K/Akt survival signaling pathway in mice," Scientific Reports, vol. 6, no. 1, p. 19869, 2016.

[35] S. Ottonello, C. Foroni, A. Carta, S. Petrucco, and G. Maraini, "Oxidative stress and age-related cataract," Ophthalmologica, vol. 214, no. 1, pp. 78-85, 2000.

[36] X. Zhang, O. A. Ibrahimi, S. K. Olsen, H. Umemori, M. Mohammadi, and D. M. Ornitz, "Receptor specificity of the fibroblast growth factor family. The complete mammalian FGF family," The Journal of Biological Chemistry, vol. 281, no. 23, pp. 15694-15700, 2006.

[37] M. Konishi, T. Asaki, N. Koike, H. Miwa, A. Miyake, and N. Itoh, "Role of Fgf10 in cell proliferation in white adipose tissue," Molecular and Cellular Endocrinology, vol. 249, no. 1-2, pp. 71-77, 2006.

[38] F. Rochais, R. Sturny, C.-M. Chao et al., "FGF10 promotes regional foetal cardiomyocyte proliferation and adult cardio- myocyte cell-cycle re-entry," Cardiovascular Research, vol. 104, no. 3, pp. 432-442, 2014.

[39] W. Li, J. Yang, J. Cai et al., "Oil body-bound oleosin-rhFGF-10: a novel drug delivery system that improves skin penetration to accelerate wound healing and hair growth in mice," International Journal of Molecular Sciences, vol. 18, no. 10, 2017.

[40] J. W. Mok, D. J. Chang, and C. K. Joo, “Antiapoptotic effects of anthocyanin from the seed coat of black soybean against oxidative damage of human lens epithelial cell induced by $\mathrm{H} 2 \mathrm{O} 2$," Current Eye Research, vol. 39, no. 11, pp. 1090-1098, 2014.

[41] A. Burlacu, "Regulation of apoptosis by Bcl-2 family proteins," Journal of Cellular and Molecular Medicine, vol. 7, no. 3, pp. 249-257, 2003.

[42] J. Du, X. Wang, C. Miereles et al., "Activation of caspase-3 is an initial step triggering accelerated muscle proteolysis in catabolic conditions," Journal of Clinical Investigation, vol. 113, no. 1, pp. 115-123, 2004.

[43] C. Yang, Y. Hong, and T. Ding, "Hydrogen saline prevents selenite-induced cataract in rats," Molecular Vision, vol. 19, no. 4, pp. 1684-1693, 2013.

[44] X. Wang, J. Sun, G. F. Dang, Y. Gao, L. Duan, and X. Y. Wu, "Antioxidant content and cytological examination of aqueous fluid from patients with age-related cataracts at different stages," Genetics and Molecular Research, vol. 14, no. 2, pp. 6251-6255, 2015.

[45] J. Bai, L. Dong, Z. Song et al., "The role of melatonin as an antioxidant in human lens epithelial cells," Free Radical Research, vol. 47, no. 8, pp. 635-642, 2013.

[46] C. H. Jin, Y. K. So, S. N. Han, and J. B. Kim, "Isoegomaketone upregulates heme oxygenase-1 in RAW264.7 cells via ROS/ p38 MAPK/Nrf2 pathway," Biomolecules \& Therapeutics, vol. 24, no. 5, pp. 510-516, 2016.

[47] Y. Naito, T. Takagi, and T. Yoshikawa, "Heme oxygenase-1: a new therapeutic target for inflammatory bowel disease," Alimentary Pharmacology \& Therapeutics, vol. 20, Supplement s1, pp. 177-184, 2004.

[48] X. An and F. Shang, "RA-XII exerts anti-oxidant and antiinflammatory activities on lipopolysaccharide-induced acute renal injury by suppressing NF- $\kappa \mathrm{B}$ and MAPKs regulated by HO-1/Nrf2 pathway," Biochemical and Biophysical Research Communications, vol. 495, no. 3, pp. 2317-2323, 2018.

[49] Y. Tian, Z. Li, B. Shen et al., "The protective effects of Shikonin on lipopolysaccharide/d-galactosamine-induced acute liver injury via inhibiting MAPK and NF- $\kappa \mathrm{B}$ and activating Nrf2/ HO-1 signaling pathways," RSC Advances, vol. 7, no. 55, pp. 34846-34856, 2017.

[50] X. Huo, C. Liu, L. Gao, X. Xu, N. Zhu, and L. Cao, "Hepatoprotective effect of aqueous extract from the seeds of Orychophragmus violaceus against liver injury in mice and HepG2 cells," International Journal of Molecular Sciences, vol. 18, no. $6,2017$.

[51] S. Zhuang, R. Yu, J. Zhong, P. Liu, and Z. Liu, "Rhein from Rheum rhabarbarum inhibits hydrogen-peroxide-induced oxidative stress in intestinal epithelial cells partly through PI3K/Akt-mediated Nrf2/HO-1 pathways," Journal of Agricultural and Food Chemistry, vol. 67, no. 9, pp. 2519-2529, 2019.

[52] C. Basu and R. Sur, "S-Allyl Cysteine Alleviates Hydrogen Peroxide Induced Oxidative Injury and Apoptosis through Upregulation of Akt/Nrf-2/HO-1 Signaling Pathway in HepG2 Cells," BioMed Research International, vol. 2018, Article ID 3169431, 2018. 
[53] X. Gao, D. He, D. Liu et al., "Beta-naphthoflavone inhibits LPS-induced inflammation in BV-2 cells via AKT/Nrf-2/HO$1-\mathrm{NF}-\kappa \mathrm{B}$ signaling axis," Immunobiology, vol. 225 , no. 4 , article 151965, 2020.

[54] J. Zhang, C. Wang, K. Kang et al., "Loganin attenuates septic acute renal injury with the participation of AKT and Nrf2/ HO-1 signaling pathways," Drug Design, Development and Therapy, vol. Volume 15, pp. 501-513, 2021.

[55] R. Canella, M. Benedusi, M. Martini, F. Cervellati, C. Cavicchio, and G. Valacchi, "Role of Nrf2 in preventing oxidative stress induced chloride current alteration in human lung cells," Journal of Cellular Physiology, vol. 233, no. 8, pp. 6018-6027, 2018.

[56] A. Giudice and M. Montella, "Activation of the Nrf2-ARE signaling pathway: a promising strategy in cancer prevention," BioEssays, vol. 28, no. 2, pp. 169-181, 2006. 